\title{
EEN MERKWAARDIGE BESLISSING
}

\author{
door F. F. van Doorne
}

De uitspraken van de Raad van Tucht resp. van de Raad van Beroep van het Nederlands Instituut van Accountants zijn voor alle accountants in het algemeen van groot belang, omdat daarin voor concrete gevallen wordt beslist, of bepaalde handelingen en gedragingen van een accountant onder gegeven omstandigheden al dan niet juist geacht mogen worden. Voor zover daarbij de accountant optrad in de zogenaamde algemene functie van de accountant, dus als vertrouwensman van het maatschappelijk verkeer, behoren deze handelingen en gedragingen dus mede getoetst te worden aan het vertrouwen, dat het maatschappelijk verkeer mag stellen in de mededelingen van de accountant. Enerzijds kan men het optreden van de vermelde organen van het N. I. v. A. zien als een optreden ten behoeve van het maatschappelijk verkeer, anderzijds vormen hun uitspraken voor de accountants een richtinggevend element bij de uitoefening van hun beroep. Mede aan de hand van deze uitspraken behoren $z$ ij in staat te zijn in voorkomende gevallen hun houding te bepalen.

Het is op grond van deze overwegingen dat mijn bijzondere aandacht werd getrokken door de, onder No. 6 - 1952 in No. 2 van de $59 \mathrm{e} \mathrm{Jaar-}$ gang van „De Accountant" (October 1952, blz. 109 e.v.) gepubliceerde uitspraak van de Raad van Tucht. Het komt mij voor, dat de inhoud van deze uitspraak zodanig kan worden gelezen, dat daarin een tegenstelling kan worden gevonden tot de, in Nederland practisch algemeen aanvaarde, leer van het gewekt vertrouwen. Afgezien van de vraag, of zulks in wezen het geval is - men kan nu eenmaal een „,case" niet ten volle beoordelen zonder het dossier bestudeerd te hebben - ben ik om de gemelde reden van mening, dat deze uitspraak critisch behoort te worden gecommentarieerd. Ik zou het betreuren, indien de in mijn ogen uit de aangehaalde uitspraak te lezen opvatting omtrent de algemene functie van de accountant ingang zou vinden; deze uitspraak mag geen school maken.

Naar ik meen is tot dusver nog geen uitspraak van een der Raden in de vakpers critisch besproken. Het lijkt mij daarom nuttig, alvorens met de eigenlijke bespreking een aanvang te maken, een enkele opmerking te plaatsen omtrent de aard van de publicaties dezer uitspraken in het algemeen.

Artikel 38 (vroeger artikel 29) van het Reglement op de Raden van Tucht en van Beroep en de Kamer voor Geschillen (verder aan te duiden als R.R.T.) bepaalt o.a., dat de beslissingen van de Raden van Tucht en van Beroep door het Bestuur verkort in het orgaan worden medegedeeld, en dat daarbij voor ogen wordt gehouden, dat de publicering ten doel heeft, bekendheid te geven aan de jurisprudentie van de Raad. Tevens blijkt uit het derde lid van dit artikel, dat omtrent de inhoud van de publicatie overeenstemming moet bestaan tussen Bestuur en Raad.

Uit dit samenstel van bepalingen mag m.i. worden afgeleid dat de verkorte publicatie ten doel heeft, van publicatie slechts die overwegingen en details uit te sluiten, die voor de beoordeling van het geval niet van betekenis worden geacht. Wil men bekendheid geven aan de jurisprudentie van de Raad, dan kan men immers geen essentiële delen van de klacht en geen essentiële overwegingen van de Raad supprimeren.

m a b blz. 354 
Wanneer derhalve in de volgende beschouwingen op leemten in de uitspraak wordt gewezen, dan moet er rekening mede gehouden worden, dat daarbij telkens een der volgende gevallen aanwezig kan zijn:

a. de leemte is veroorzaakt doordat de Raad het betreffende punt niet heeft onderzocht, resp. daarvan niet in de uitspraak heeft doen blijken;

b. de leemte is veroorzaakt, doordat het Bestuur het betreffende punt heeft gesupprimeerd, daarmede er blijk van gevende, dat het dit niet van essentiële betekenis heeft geacht, en zulks in overeenstemming met de Raad.

Uiteindelijk moet men dus wel tot de conclusie komen, dat de publicatie het standpunt en de daartoe leidende overwegingen van de Raad juist weergeeft. Wel is het te betreuren, dat de plaatsen, waar verkortingen werden aangebracht, niet als zodanig duidelijk zijn vermeld. De tekst doet niet vermoeden, dat daaruit méér is verwijderd dan namen en data, dus inderdaad voor de doelstelling der publicatie volkomen irrelevant zijnde feiten. Echter ontbreekt tussen de overwegingen 7 en 9 een overweging 8 , en de lezer wordt in het onzekere gelaten, of deze bewust is gesupprimeerd, dan wel tengevolge van een slordigheid niet is afgedrukt.

Thans allereerst de casus. In eigen woorden weergegeven ging het om

(1.) een opdracht tot waardering van aandelen ener Naamloze Vennootschap (door de accountant dier Vennootschap? en) in opdracht van de Directie.

Het is duidelijk, dat deze opdracht behoort tot het deelgebied der bijzondere onderzoekingen. De theorie leert, dat hierbij veelal een nadere omschrijving van de doelstelling noodzakelijk is. Waarom bestond er behoefte aan een waardering door een accountant? Wat was de wezenlijke strekking van de opdracht? Deze nadere omschrijving ontbreekt zowel in de weergave van de klacht als in de daarop volgende overwegingen van de Raad, tezamen omvattende de eerste zeven punten van de publicatie. In punt 9 wordt, als nader bij de mondelinge behandeling gebleken, vermeld dat het rapport bestemd was ter inlichting van een toekomstig aandeelhouder. De doelstelling was dus de vaststelling van, althans een advies omtrent, een emissiekoers.

Het verwondert mij, dat deze doelstelling niet reeds bij de formulering van de klacht is vermeld. $\mathrm{l}$ acht haar een noodzakelijk gegeven voor de accountant om de opdracht goed te kunnen uitvoeren en dus evenzeer voor de Raad om zijn uitspraak te kunnen geven. Het is natuurlijk mogelijk, en in casu zelfs waarschijnlijk, dat de omschrijving van de doelstelling in de klacht heeft ontbroken. Het zou dan echter naar mijn mening op de weg van de Raad hebben gelegen am, onder toepassing van artikel 14, lid 3, R.R.T. ,de klager uit te nodigen zijn... klacht te verduidelijken".

$\mathrm{Nu}$ uit de gepubliceerde uitspraak vóór punt 9 niets blijkt omtrent de specifieke doelstelling kon de Raad dus moeilijk in zijn beschouwingen vóór punt 9 de vraag betrekken, welke waarde was bedoeld en welke inlichtingen voor dit geval vereist waren, teneinde het vertrouwen, dat in de verklaring van de accountant wordt gesteld, niet te beschamen. Dit zou nog geen bezwaar behoeven te zijn, wanneer dan maar in de uitspraak vóór punt 9 de hoogste maatstaf aan de inhoud van de verklaring ware 
aangelegd. De nadere omschrijving van de doelstelling wordt immers vereist, om het onderzoek daarop in het bijzonder te richten, en dusdoende overbodige werkzaamheden en overbodige mededelingen te vermijden. Zonder deze nadere omschrijving dient de verklaring zodanige inlichtingen te verschaffen, dat ze voor alle deelnemers aan het maatschappelijk verkeer gelijkelijk bruikbaar is; dus zowel voor de huidige als de toekomstige aandeelhouder, de huidige als de toekomstige credietverstrekker, de fiscus, enz. Evenzeer zou aandacht moeten worden gewijd aan de vraag, of er plaats zou zijn voor afwijkende waardering voor minderheidsen meerderheidsbelangen, en voor overige mogelijke belangengroeperingen. Zonder te willen beweren, dat hiermede alle denkbare gevallen vermeld zijn is deze opsomming voldoende om te constateren, dat de uitvoering, de rapportering en ook de beoordeling door de Raad aanmerkelijk verzwaard worden door de specifieke doelstelling van een bijzonder onderzoek te verwaarlozen. Ik ben dan ook van mening, dat de theorie haar eis terecht stelt.

De door mij opgeworpen vraag, of de opdracht werd uitgevoerd door de accountant der Vennootschap is, objectief gezien, niet van belang. Ongeacht $z$ ijn relatie tot de Vennootschap zal de accountant zijn werkzaamheden als objectief en onpartijdig deskundige moeten verrichten. De uitspraak vermeldt omtrent deze vraag niets positiefs; wel meen ik tussen de regels te lezen (zie b.v. punt 3, waarin sprake is van een voorlopige balans en een later op te stellen fiscale balans), dat beklaagde reeds accountant der Vennootschap was. Een ogenblik aannemende, dat dit inderdaad het geval was, zou dit hoogstens kunnen medebrengen, dat bij deze accountant op grond van zijn regelmatige contrôle de meest mogelijke kennis van de bijzondere omstandigheden der Vennootschap, zowel wat haar verleden als wat haar huidige ontwikkelingstendenties betreft, aanwezig kan worden geacht; een accountant, die niet reeds eerder met de contrôlefunctie bij de Vennootschap was belast zou mogelijk bij zijn onderzoek niet al deze bijzondere omstandigheden hebben leren kennen, al zou hij op grond van zijn deskundigheid veel daarvan hebben moeten vermoeden, en daarop zijn onderzoek mede moeten gericht hebben. Wanneer dus in casu sprake zou zijn geweest van een reeds aanwezige contrōlefunctie zou dit de aan te leggen eisen naar mijn mening slechts hebben kunnen verzwaren.

Hetzelfde geldt min of meer ten aanzien van de positieve mededeling, dat het rapport werd uitgebracht in opdracht van de Directie. Ook dit feit verandert niets aan de daadwerkelijke functie van de accountant, n.l. die van vertrouwensman van het maatschappelijk verkeer. De theorie leert, dat de juridische opdrachtgever voor de omvang van de contrôle en de opstelling der verklaring slechts een ondergeschikte rol speelt. $\mathrm{H}_{\mathrm{ij}}$ roept door zijn opdracht de specifieke functie in het leven, en geeft de doelstelling aan. Het juridische gevolg, dat hij de rekening moet betalen, legt noch voor de taakbepaling, noch voor de opstelling dor verklaring enig gewicht in de schaal. Ook hier kan de vermelding van de juridische verhouding slechts verzwarend werken op de eisen, waaraan door de Raad de verklaring wordt getoetst.

Beide detailpunten komen echter in de uitspraak niet respectievelijk verder niet meer ter sprake, zodat ik daaromtrent met deze algemene opmerkingen meen te kunnen volstaan. 
Wat bevatte nu dit rapport? Blijkens de klacht was dit een becijfering van

(II.) de intrinsieke waarde, waarbij o.a. niet was vermeld, dat het belangrijkste deel der activa aan crediteuren tot zekerheid was overgedragen, en evenmin, dat op een aan de N.V. toebehorend pand door de fiscus was beslag gelegd voor een vordering, groot $80 \%$ van de balanswaarde van dit pand.

Blijkens het opschrift boven de gepubliceerde uitspraak is het niet vermelden van de genoemde feiten niet beschouwd als een handeling als bedoeld in artikel 1 R.R.T. Deze handelingen zijn volgens de oude redactie, waaronder vermoedelijk deze uitspraak is gegeven:

a. handelingen in strijd met de goede trouw;

$b$. een ernstig tekort aan nauwgezetheid in de uitoefening van het beroep van accountant;

c. andere handelingen, schadelijk voor het aanzien van de stand van accountant;

d. alle overige handelingen in strijd met de statuten en reglementen van het Instituut.

De Raad betoogt in de punten 4 en 5 , dat het overdragen tot zekerheid van, en het beslag op, in de berekening opgenomen activa de intrinsieke waarde, zijnde het verschil tussen activa en passiva, niet aantasten. Dit betoog, dat formeel juist lijkt, kan mij desondanks niet bevredigen.

Uit het gestelde in (II.) is wel op te maken, dat de financiële toestand der Vennootschap vermoedelijk niet rooskleurig was. De gestelde feiten in hun onderling verband doen vermoeden, dat er overmatig veel crediteuren waren, en daaronder meerdere, die allerminst gerust waren op de toekomstige ontwikkeling der Vennootschap, zodat zij het nodig hadden geoordeeld, zich een bevoorrechte positie te verschaffen. $\mathrm{Nu}$ is het duidelijk dat, wanneer een of meer crediteuren van deze hun rechten gebruik zouden gaan maken, de verbonden activa, uit hun verband gerukt, te gelde zullen worden gemaakt en dat dan met een veel lagere opbrengst dan die van de going-concern value zal moeten worden gerekend. Onder de geschetste omstandigheden zou dus veeleer de liquidatiewaarde bij de waardering in overweging moeten worden genomen dan de intrinsieke waarde, waarbij ik aanneem dat deze laatste term in het algemeen slechts wordt gebruikt ter aanduiding van een waardering op going-concern basis.

Bevreemdend is, dat in de uitspraak deze kant van de zaak niet wordt vermeld. $\mathrm{Nu}$ is het natuurlijk mogelijk, dat de berekening der intrinsieke waarde in feite op liquidatie-basis heeft plaats gevonden, zodat de Raad in casu tot zijn beslissing mocht komen. De strekking van mijn betoog is dan ook geen andere dan om aan te tonen, dat de overwegingen van de uitspraak geen algemene strekking kunnen hebben, zodat in ieder geval de in de publicatie boven de uitspraak geplaatste, wèl algemeen gestelde kern, gevaren oplevert voor onjuiste interpretatie. Ik ben zeer stellig van mening dat de accountant, die de inlichting, dat in zo belangrijke mate activa verbonden zijn, verzwijgt in zijn rapport, in het algemeen een handeling verricht, die blijk geeft van een ernstig tekort aan nauwgezetheid. Hij geeft immers een goedkeurende verklaring af omtrent de intrinsieke waarde, zonder daarbij te vermelden, dat er waardedrukkende invloeden aanwezig zijn, die niet uit de gegevens blijken; hij onthoudt aan 
degene, die van zijn rapport kennis neemt gegevens, die deze nodig heeft om zijn oordeel te vormen. Hierbij blijft dan nog onbesproken de vraag. of de accountant, als deskundige op het gebied der bedrijfseconomie, niet zeer nadrukkelijk in zijn rapport aandacht had behoren te schenken aan de vraag, of voor het vaststellen van een emissiekoers de intrinsieke waarde c.q. de liquidatiewaarde in het algemeen een juiste maatstaf is, en hoe naar zijn mening in het betreffende geval daarover door hem wordt geoordeeld. Ik ben van mening dat de accountant, die de opdracht krijgt om een berekening te maken van de waarde van aandelen, en in zijn rapport uitsluitend de intrinsieke waarde zou aangeven, daarmede het vertrouwen zou wekken, dat deze door hem vermelde waarde inderdaad mag worden beschouwd als de waarde dezer aandelen. En ik geloof dat dit slechts bij uitzondering het geval zal zijn.

Naast de genoemde waarden dient immers bij een waardering van aandelen in het algemeen eveneens de rentabiliteit der onderneming c.q. het rendement der aandelen in de beoordeling te worden betrokken. Dit klemt in dit geval temeer, omdat de wezenlijke doelstelling van de opdracht niet, althans in dit stadium nog niet, is vermeld en dus niet in het oordeel van de Raad kan zijn betrokken, zodat het rapport voor alle deelnemers aan het maatschappelijk verkeer bruikbaar behoort te zijn. Het rapport nu vermeldt daaromtrent (punt 3), kort weergegeven:

(III.) de rentabiliteitswaarde is geheel buiten beschouwing gelaten. omdat voor het toekomstig rendement geen juiste maatstaf wordt gevonden in de zeer uiteenlopende resultaten van de voorgaande jaren; het opstellen van een rendementsbegroting wordt geheel aan het eigen inzicht van de opdrachtgever (in casu de Directie) overgelaten.

Thans in het midden latende in hoever het weergegevene blijk geeft van een juist standpunt van de accountant zou ik er op willen wijzen, dat er naar mijn mening geen plaats is voor een goedkeurende verklaring, wanneer daarbij een restrictie wordt gemaakt van een dermate wijde strekking. Het weergegevene wil immers zonder meer zeggen, dat de toekomstige rentabiliteit kan liggen tussen min oneindig en plus oneindig - hetgeen een schop tegen een open deur is - en wanneer men niet in staat is hierover iet of wat concreter te zijn dan betekent dit, dat de waarde der aandelen onmogelijk kan worden vastgesteld. Het afgeven van een goedkeurende verklaring uitsluitend omtrent de intrinsieke waarde met dergelijke restricties is naar mijn mening in strijd met art. $12 \mathrm{R}$. v. A., waarin wordt gezegd, dat het de leden verboden is een goedkeurende verklaring met voorbehoud af te geven, indien dit voorbehoud de strekking der verklaring teniet doet of aan deze strekking wezenlijk afbreuk doet. Ik laat daarbij nog in het midden, dat in de uitspraak niet van een voorbehoud, doch van ",restricties" gesproken wordt, terwijl artikel 11, eerste lid, R. v. A., uitdrukkelijk het gebruik van de woorden .,onder het voorbehoud" voorschrijft, en het tweede lid daaraan toevoegt, dat uit de omschrijving der bedenkingen duidelijk de draagwijdte moet blijken.

Het lijkt mij overigens bepaaldelijk onjuist, het opstellen van een rendementsbegroting geheel aan het inzicht van een der belanghebbenden over te laten. Men zou dan toch minstens een aantal voor de beoordeling van een dergelijke begroting belangrijke data uit het verleden in het rapport moeten 
vermelden. Zoals het nu gesteld is heeft de Directie alle vrijheid, bij die begroting uit te gaan van omzetcijfers en kostenverhoudingen, die bepaaldelijk als onwaarschijnlijk zouden dienen te worden gebrandmerkt; de lezer van het rapport kan echter deze conclusie niet trekken, wanneer totaal geen cijfermateriaal is verstrekt. En zulks meen ik te mogen aannemen op grond van punt 9 , waarin de klager zich beklaagt, dat er meer inzicht had moeten zijn gegeven omtrent de gang van zaken bij de Vennootschap. De Raad meent, dat deze grief faalt. Een duidelijke motivering hiervan heb ik niet kunnen vinden, doch vermoedelijk is dit gebaseerd op de overweging van het derde lid van punt 10 , waaruit blijkt, dat na het uitbrengen van het rapport nog mondeling door beklaagde verschillende inlichtingen aan de accountant van klager zijn verstrekt. Nu blijkt niet, welke inlichtingen hier bedoeld zijn, en nog minder dat de accountant van klager hieromtrent als getuige is gehoord, zodat hierop niet nader kan worden ingegaan. Het zou wel interessant zijn geweest te vernemen, welke visie de accountant van klager op deze zaak had.

Ik meen echter wel hier te mogen zeggen, dat het naar mijn mening als een ernstige omissie in het rapport moet worden beschouwd, wanneer dergelijke belangrijke gegevens daarin ontbreken, zodat het rapport later mondeling of schriftelijk moet worden aangevuld. Ik voor mij zou uit deze beslissing niet willen concluderen, dat tegen een onvolkomen rapport geen bezwaar meer kan worden gemaakt, wanneer het tegenover een bepaald persoon nader is toegelicht.

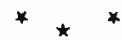

Zoals hierboven bij (I.) vermeld, bleek de eigenlijke doelstelling van de opdracht het verstrekken van inlichtingen ten behoeve van een toekomstig aandeelhouder. Punt 9 vermeldt hieromtrent:

(IV.) het napport vormde een grondslag voor onderhandeling tussen de Vennootschap en klager over het verstrekken door deze van nieuw kapitaal.

Onweersproken wordt hierbij door klager gesteld, dat de accountant dit heeft geweten, en dat hij daarom meer inzicht had moeten geven omtrent de gang van zaken.

Het komt mij voor, dat het becijferen van de intrinsieke waarde met restricties als bij (III.) vermeld, moet leiden tot de gevolgtrekking, dat er ernstig gevaar bestaat voor misleiding van de lezer van het rapport. De lezer van het rapport, of zoals wij deze in het algemeen in de theorie aanduiden als ",de verstandige leek", in dit geval de toekomstige aandeelhouder, moet toch uit een dergelijk rapport een stellige conclusie kunnen trekken, moet voor zijn voorgenomen handeling in dit rapport een gids vinden. Door uitsluitend de intrinsieke waarde te vermelden, zij het dan met restricties, wordt in elk geval gesuggereerd, dat deze intrinsieke waarde een goede grondslag biedt voor de onderhandelingen. Ik ben van mening dat uit de gegevens blijkt, dat zulks minstens aan twijfel onderhevig is.

De Raad heeft in punt 10 ,ten overvloede" aan dit punt aandacht geschonken, doch geconcludeerd, dat ook deze grief faalt, omdat

$(V$.$) in het rapport zeer duidelijk restricties zijn gemaakt ten opzichte$ van wat beklaagde wel en wat hij niet heeft berekend. 
De bewoordingen die hier gebruikt worden doen sterk denken aan wat men wel noemt de positieve en de negatieve taakomschrijving. Het zijn deze min of meer verkapte vormen van het voorbehoud, die door de vertrouwensleer worden verworpen, omdat de verstandige leek, de lezer dus van het rapport, de draagwijdte van deze omschrijvingen niet kan beoordelen. Naar mijn mening is de redactie van het tweede lid van artikel 11 R. v. A., hierboven bij (III.) weergegeven, een uitvloeisel van deze in de theorie ontwikkelde stelling.

Resumerende meen ik derhalve, dat uit de Uitspraak niet te lezen is - eerder het tegendeel is af te leiden - dat de volgende stellingen, gedeeltelijk ontleend aan de theorie der accountantscontrōle op de grondslag van de vertrouwensleer, gedeeltelijk aan de bedrijfseconomie, als juist dienen te gelden:

1e. bij de bijzondere onderzoekingen kan als regel een duidelijke omomschrijving van de doelstelling niet gemist worden;

2e. het bij de berekening van de intrinsieke waarde van aandelen niet vermelden, resp. het buiten beschouwing laten van de omstandigheid, dat een belangrijk deel der activa is verbonden ten behoeve van bepaalde crediteuren kan, en zal in vele gevallen, tot een onjuist inzicht in de (intrinsieke) waarde dezer aandelen leiden;

$3 e$. het geheel buiten beschouwing laten van rentabiliteit resp. rende. ment c.q. het niet vermelden van de uit het verleden bekende gegevens daaromtrent bij een dergelijke waardebepaling is in beginsel onjuist;

4e. een voorbehoud dient stellig en ook voor de niet-ingewijde duidelijk te $z$ ijn; de draagwijdte en de gevolgen van het voorbehoud moeten worden aangegeven;

$5 \mathrm{e}$. noch de positieve, noch de negatieve taakomschrijving voldoen aan deze eisen.

Hoe juist de uitspraak in het gegeven geval voor de betrokken accountant misschien moge zijn geweest, op bovenstaande gronden is zij naar mijn mening door haar formulering noch voor de theorie, noch voor de praktijk, bruikbaar als richtinggevend element. 